\title{
Kripke's Principle of Disquotation and the Epistemology of Belief Ascription
}

Andreas Kemmerling

Dedicated to an anonymous referee of $\mathrm{Mind}$

Saul Kripke, in his paper "A puzzle about belief", tells us a story about Pierre, a story which could easily be true in the world as we know it. The story doesn't contain any so-called twin worlds or molecule-tomolecule identical people. In this respect it is more innocent than many other philosophical thought experiments of the recent past. But even without any such dramatic devices it seems to point to possibilitiesand what is more, to "realistic" possibilities-which seem to contain a lot of philosophical dynamite.

I shall suppose that Pierre's story is, by now, common knowledge among philosophers and therefore a short reminder will do. Pierre was a normal speaker of French, before he moved to London and learnt English without ever using any dictionary or similar devices. During his time in France he had heard about London, and because of what he had heard, he acquired the disposition to assent to the sentence "Londres est jolie", a disposition he still has. After a time in England, he becomes a normal speaker of English, and what he has seen of London inclines him to assent to the sentence "London is not pretty". ${ }^{1} \mathrm{He}$ fails to no-

Let me mention one aspect of this story which may seem dubious. It is of some importance for Kripke's considerations that Pierre is a normal speaker of English and French. But given Pierre's peculiar linguistic history and given, in particular, his lack of knowledge concerning the fact that the city he refers to as "Londres", when he speaks French, is London, the city he refers to as "London", when he speaks English-given this, can he really be considered a normal speaker of English and French?

Kripke assumes this point without arguing it in detail, and I think he is right. Pierre is a normal speaker of English, in the sense employed by Kripke: When Pierre uses normal sentences of English for the normal linguistic purposes of asking, giving information etc., the words he uses have just the sense and reference they would in the mouths of other normal speakers of English. He also, and for corresponding reasons, is a normal speaker of French.-Nevertheless, it has to be conceded that there is a reading of the phrase "a normal speaker of English and 
tice that the city he refers to as "Londres" when he speaks French is the same city as the one he refers to as "London" when he speaks English.

Let us assume that he sometimes says "London is not pretty" when conversing with his English friends, and that he sometimes says "Londres est jolie" when talking to his French friends. We seem to be compelled, by accepted principles of our ordinary practice of belief ascription, to say that he believes that London is not pretty (on the strength of his assent to "London is not pretty"); at the same time, we seem compelled to say that he believes that London is pretty (on the strength of his assent to "Londres est jolie"). ${ }^{2}$

What exactly is the puzzle allegedly contained in the story? Kripke, in the title of his paper, calls it a puzzle about belief, and in the opening sentence a puzzle about names and belief. ${ }^{3}$ So is it a puzzle about the common concept of belief? ${ }^{4}$ Or about the semantic role of proper names (like "London" and "Londres") in belief-sentences? ${ }^{5}$ Or about strange results of the application of what appear to be uncontroversial principles for the ascription of beliefs? ${ }^{6}$ Or about the conceptual relationship between rationality and holding beliefs which appear to be straightforwardly contradictory?

The extensive literature on Kripke's story about Pierre shows that it inspires thoughts about everything that $I$ have just mentioned. And part of what makes it such a fascinating story is that it is simple and innocent, yet still has so many puzzling features. In the following, I shall concentrate on one aspect of the puzzle, which concerns the epistemology of belief ascription. The question I shall address is whether we are compelled, by our ordinary practice of belief ascription, to ascribe to Pierre the belief that London is not pretty on the strength of

French" in which it may not apply to Pierre. He may not be a normal bilingual speaker of English and French. Yet in this there lurks no difficulty which concerns us here. The principles of belief ascription to which Kripke appeals require only that Pierre is a normal speaker of English and a normal speaker of French. It is irrelevant if he is a normal bilingual.

2 Kripke (1979), p. 257.

3 Kripke (1979), p. 239.

4 This is what K. Donnellan (1989) argues for.

5 See, e.g., D. Lewis (1981), B. Loar (1987) and D. Sosa (1996).

6 See, e.g., J.I. Biro (1984) and D.E. Over (1983) who claim that Kripke misapplies the principle of disquotation and the principle of translation, respectively. According to J.G. Moore (1999), Kripke fails to observe that the application of the principle of disquotation is not a mechanical matter but has to be guided by "contextualist" considerations.

7 See, e.g., R.B. Marcus (1981) and N. Feit (2001). 
his assenting to the sentence "London is not pretty" (or the belief that London is pretty on the strength of his assent to "Londres est jolie"). I shall try to show that we have no principled justification for ascribing to Pierre either of the two beliefs, and moreover that we have some reason to assume that he does not have either of them.

Let me make it clear right at the beginning that my aim is not primarily to solve or dissolve the puzzle about belief. Nevertheless, if what I shall argue is correct, then the puzzle as it has been presented by Kripke himself does not arise. But this is not meant to point to the "real" or "ultimate" solution of the puzzle. If a similar type of case could be created even without any principle of disquotation, ${ }^{8}$ then this would not affect what I want to argue for in this paper. What I shall take issue with is Kripke's principle of disquotation and how it is applied in creating the puzzle. ${ }^{9}$ This principle, its peculiar epistemological status and its special justificatory role in belief ascription are of philosophical interest in their own right; in particular, it is instructive, I hope, to see why it is not applicable in a case like the one of Kripke's Pierre.

My argument will run as follows. I replace Kripke's disquotational principle by a modified version and then argue that this modified principle cannot be invoked to justify the ascription of the belief that London is not pretty (or of the belief that London is pretty) to Pierre. It cannot be invoked because Pierre's case is abnormal; and I shall defend this claim against the charge of being ad hoc. Moreover, I shall argue that Pierre does not express the belief that London is not pretty by his assent to "London is not pretty", and, more generally, that there is no principled justification for ascribing to Pierre, or denying him, the beliefs in question. Nevertheless, there is some reason to think that he does not have these beliefs. In the second part of the paper I sketch a general line of defence for the suggested revision of the disquotational principle: It belongs to a family of conceptually true generalizations of which it is characteristic that they contain a general normality constraint essentially. In sections 6 and 7, I shall try to refute Kripke's specific arguments against denying that Pierre believes that London is pretty/not pretty.

D. Sosa (1996, p. 384) tries to show that it can. But see J.G. Moore (1999, pp. 359f.) for reasons to doubt that Sosa's attempt is successful.

I shall not be concerned here with Kripke's principle of translation which he employs in ascribing to Pierre the belief that London is pretty on the strength of his assent to "Londres est jolie". 


\section{A modification of the disquotational principle}

Kripke states his so-called disquotational principle as follows:

If a normal English speaker, on reflection, sincerely assents to " $p$ ", then he believes that $p$. (Where " $p$ " is to be replaced inside and outside all quotation marks by any appropriate standard English sentence.) $)^{10}$

This is not exactly right as it stands since an important qualification is missing, which is, as I shall argue in sections 4 and 5, characteristic of all generalizations of this kind: namely a qualification concerning overall normality of the circumstances. The principle would at least have to be modified in the following way:

If a normal English speaker, on reflection, sincerely assents to " $p$ ", then, ceteris paribus ${ }^{11}$, he believes that $p$.

Adding an overall normality constraint, the ceteris paribus clause, to a generalization is not in itself a way of making the generalization immune to falsification. Rather it is a way of drawing a distinction among possible counterinstances: a distinction between those which are genuine falsifications and those yet unthought-of interferences which should not be considered as falsifications. A generalization like "Ceteris paribus, ripe lemons are yellow" is not falsified by ripe lemons which have been painted blue, or by lemons which are blue because they were exposed to some special kind of radiation during their ripening process in a lab; but, in spite of the normality constraint, it would be genuinely falsified, if we, e.g., hit upon a new sort of lemon which are blue when ripe. A flexible all-purpose proviso like the ceteris paribus clause is exactly what we need, whenever we have reason to believe that there are

10 Kripke (1979), pp. 248f. He adds: 'The sentence replacing ' $\mathrm{p}$ ' is to lack indexical or pronominal devices or ambiguities, that would ruin the intuitive sense of the principle".

11 Erudite readers have reminded me of the fact that, strictly literally speaking, the term "ceteris paribus" is not exchangeable with "under overall normal conditions". Strictly speaking, "ceteris paribus" is a qualifier designed only for contrastive statements like: "Of any two Rolling Stones fans, one male and one female, the male will like Keith's singing better than the fermale". It is not designed to qualify a statement like "Whenever an iron rod is heated, it expands".-But since, alas, nobody seems to care, I prefer not to care either. I have chosen "ceteris paribus" because it seems to be the most indeterminate normality-operator in current philosophical use. Read it as saying: "given overall normal conditions" or "with some qualification concerning overall normality". 
possible counterinstances which would not genuinely falsify the generalization "as it is meant in the first place" but have no hope of specifying a comprehensive list of them in advance. The point of introducing such a proviso is not to allow for ad hoc rejections of genuine falsifications (i.e., the hedged generalization must not be read as amounting to: "Ripe lemons are yellow, unless they aren't"), but rather for appropriate and balanced rejection of spurious falsifications. ${ }^{12}$

In applying this revised principle to Pierre, we have enough ascriptional leeway at hand to avoid the conclusion that he believes that London is not pretty, while still granting that he is a normal speaker of English who, on reflection, sincerely assents to "London is not pretty". (One terminological remark. For the sake of less convoluted speech, I shall often just say "assent to" without mentioning explicitly the qualifications of seriousness and reflectedness; so when I say in the following of somebody that he assents to a sentence, this is to be understood as saying that he assents to it sincerely and on reflection.)

Let me repeat the point of the modification just introduced, for it is crucial. The corrected version of the disquotational principle allows for the following possibility: $x$ is a normal speaker of English; $x$ assents to "London is not pretty"; but $x$ does not believe that London is not pretty. It allows for this possibility, because of the ceteris paribus clause. This clause becomes pertinent in Pierre's case.

Why? Well, when Pierre assents to "London is not pretty", there is at least one feature which is highly bewildering and deviant from normal cases. In fact, it is so bewildering and deviant that it should prevent us from rashly conceding that he believes that London is not pretty. The feature which I have in mind is this: When Pierre assents to "London is not pretty", he also, at the same moment, has the disposition to assent to another sentence which I shall call a counter-sentence. Two sentences, $s$ and $s^{*}$, are counter-sentences of each other (at context $c$ ) iff assent to $s$ (at $c$ ) is, ceteris paribus, a way of expressing a particular intentional attitude $a$, and assent to $s^{*}$ (at $c$ ) is, ceteris paribus, a way of expressing the lack of $a .{ }^{13}$ Correspondingly, I shall call the simultaneous

12 Let me emphasise that in saying this, I do not mean to address the thorny topic of the appropriateness of ceteris paribus clauses in laws of the special sciences and in physics. See Erkenntnis 57 (2002) for an excellent collection of papers which reflect the current state of the debate on this issue. My remarks here only concern the use of these clauses in generalizations as they occur in non-scientific discourse.

13 Both assenting to "It is not the case that $p$ " and to "I do not believe that $p$ " are considered here as ways of expressing lack of belief that $p$. (Expressing disbelief that $p$ counts, ceteris paribus, as a way of expressing lack of belief that $p$.) I assume 
dispositions to assent to two such sentences counter-dispositions of each other. And I shall call them attitudinal dispositions, because manifesting them is, ceteris paribus, manifesting a particular intentional attitude or the lack of it.

Now the crucial point is this. If somebody has, and is known to have, both an attitudinal disposition and a counter-disposition of it, then the attitude in question cannot be ascribed to him solely on the strength of manifesting the disposition. Neither can the lack of the attitude be ascribed to him solely on the strength of manifesting the counterdisposition. These two attitudinal dispositions cancel each other out, as it were, as indicators of particular attitudes.

In the dialectical context of Kripke's puzzle, this claim may seem ad boc, reflecting nothing but a rationalistically prejudiced philosopher's aversion to ascribing contradictory beliefs. Against this, two things should be noted. First, the ascription of contradictory beliefs is not at all ruled out thereby. What is denied is just this: that the disquotational principle compels us to ascribe contradictory beliefs solely on the strength of assent to sentences towards which the speaker is known to be counterdisposed. (If we allow for the possibility that a normal speaker who is not relevantly counter-disposed may, on reflection, sincerely assent to " $p$ and it is not the case that $p$ ", then even the modified principle can be invoked in order to ascribe contradictory beliefs.) Second, it is not philosophical prejudice but rather appears to be a plain fact about our common ordinary practice of belief ascription that we would not (consider ourselves compelled to) ascribe a belief solely on the strength of assent if we knew (or had reason to think) that the assenter is counterdisposed. More on this in a moment.

\section{Does Pierre express the beliefs?}

Questions about whether a subject expresses a certain belief (and whether therefore this belief can be ascribed to him with principled justification) should be distinguished from questions about whether the subject has the belief in question. And these factual questions, whether someone really has or expresses a certain belief, should also be distinguished from

that this pattern is valid not only of belief but of all propositional attitudes which can be expressed, but nothing in the following depends on this assumption.-Are "The morning star is visible in the sky" and "The evening star is not visible in the sky" counter-sentences? I shouldn't say so, but if you prefer a less fine-grained individuation of propositional attitudes, this will pose no problem for the considerations in this paper. 
epistemological questions concerning the justification for ascribing this belief to him or for claiming that he expresses it by what he does. These distinctions are germane to the ensuing considerations, because I want to argue that Pierre definitely does not express the belief that London is not pretty by assenting to "London is not pretty"; but that nothing definite can be said about whether Pierre holds this belief. And as regards matters of justification, it is important to see that Pierre's imagined English listeners (who are part of the story) may be justified in assuming that he expresses this belief by assenting to "London is not pretty" and therefore justified in ascribing to him this belief, whereas, we-the readers of Kripke's story who are in the know about his counterdispositions-are not justified in ascribing to him this belief, since we know that he does not, despite all appearances, express this belief by his assent.

Let me briefly elaborate on this last point first. In considering problems like the ones we are dealing with in this paper, it is of great importance to clearly distinguish two bodies of knowledge concerning the situation to be analysed. On the one hand, there is the knowledge which we, the external analysers, have about the situation; we know, for example, that Pierre is disposed to assent to "Londres est jolie". On the other hand, there is the knowledge which they, the people who populate the fictional situation described by Kripke, have about the situation. They, Pierre and his English audience, don't know that he has any counter-disposition to his assent to "London is not pretty". (Pierre may know that he is disposed to assent to "Londres est jolie", but he does not know that this is a counter-disposition of his disposition to assent to "London is not pretty"; his audience may know that the two dispositions are counter-dispositions of each other, but they do not know that Pierre has both of them.) If we do not clearly distinguish between us and them-when we, for example, surreptitiously imagine ourselves being in their situation-, then we may easily get confused.

Having read Kripke's story, we are, as I shall argue, in a position to know that Pierre does not express the belief that London is not pretty, when he assents to "London is not pretty". Yet they are perfectly justified in ascribing this belief to him on the strength of his assent. They are perfectly justified in doing this, since Pierre's assent, which they mistakenly but justifiably consider a normal case of assent, creates a presumption on their behalf that he believes that London is not pretty, and there is no salient feature of the situation which could reasonably stop them from making their judgement in accordance with this presumption. We are in a relevantly different epistemic situation. Informed 
by Kripke that Pierre is counter-disposed, we know that there is something abnormal involved, so his assent does not create such a presumption on our behalf. To think otherwise is to confuse us with them. If they knew what we know, they would not consider the case a normal one; they would therefore not ascribe to Pierre the belief that London is not pretty solely on the strength of his assent to "London is not pretty". They would, one may guess, ask Pierre "Now what is it that you think about London? To us you say that it is not pretty, to your French friends you say that it is pretty. Tell us what you really think." Kripke's story leaves it open what Pierre's considered answer would be as soon as he has recognized that "Londres" and "London" are names of the same city. And therefore, as I shall argue, it leaves it open whether or not Pierre believes that London is pretty.

At the end of the first section I had mentioned the suspicion that the claim that Pierre's assent is not a normal case of assent may be ad boc. Now it should be obvious both why it is not ad boc and why it may seem so in the dialectical context of Kripke's puzzle. It may seem ad boc because from the standpoint of anybody involved in the story, Pierre's assenting is bound to appear to be a fully normal case. Moreover, the people in Kripke's story cannot be blamed for taking this case as a normal one (after all, it took Kripke's ingenuity to discover this remote possibility at all). The appearance of overall normality is not due to a mistake or some sort of epistemic negligence of Pierre or his audience. So, given normal knowledge and due epistemic care concerning the situation in which Pierre assents to "London is not pretty", his assenting appears to be a normal case; hence it may easily seem to be ad boc to claim that it is not a normal case.-But nevertheless the claim is not ad hoc. For it is quite generally true that counter-disposedness is an abnormal feature in situations in which we want to ascribe beliefs to people on the basis of what they say. Moreover, it is not "normal" knowledge of the situation which proves decisive for whether the situation is normal, but rather complete knowledge of the relevant features. Quite generally and independently of Pierre's particular case, if we really knew, or were aware of a good reason to assume, that somebody is prepared at the same time both to say that $p$ and to say that non- $p$, his sincerely saying the one thing or the other depending only on whether he happens to speak English or French, then what he says alone would not settle for us that he believes that $p$ or non- $p$ respectively.

Now let us first consider the question whether Pierre, by assenting to "London is not pretty" expresses the belief that London is not 
pretty. ${ }^{14}$ We should note right at the start that, even if he does not express this belief, it is still an open question whether he has it. Facts about believing are quite independent from facts about belief-expression: One may have a belief but not express it, and vice versa.

Expressing a belief is more than merely providing any sort of evidence whatever that one has the belief. Rather it is performing some action which yields principled justification, of a special kind, for the ascription of the belief. An ascription principle is any generalization of the kind "If someone does $x$, and such-and-such conditions are satisfied, then, given overall normal conditions, he believes that $p$ ". What makes belief expression special is the basic nature of the ascription principle (in virtue of which doing $x$ is an expressing of the belief that $p$ ). A basic ascription principle is, first, fully uncontroversial, a piece of common knowledge (i.e., it is accepted by everyone, known to be so, etc.); and second, its truth is conceptual. ${ }^{15}$ If we were to know that the antecedent of a basic ascription principle is satisfied by $S$ 's doing $x$ at $t$, and that the relevant conditions are satisfied at $t$, we would be "forced" to admit: If overall normal conditions obtained at $t, S$ at $t$ believed that $p$. And to the extent that we have no reason to assume the presence of anything abnormal, we are "forced" to ascribe $S$ the belief that $p$.-In brief, I suggest the following:

In doing $x, S$ expresses the belief that $p$, iff (roughly) there is an accepted conceptually true principle of the type "If someone does $x$, and conditions $c_{1}, \ldots, c_{n}$ are satisfied, then, ceteris paribus, he believes that $p^{\prime \prime}$, and in doing $x, S$ satisfies the antecedent of such a principle. ${ }^{16}$

14 Does a phrase of the form "the belief that ..." refer at all? Isn't there maybe something fishy about the definite article? It can't be denied, as, e.g., Moore (1999) has argued, that the same phrase of the type "the belief that $p$ " or "... believes that $p$ " may denote different things relative to different contexts, even if " $p$ " is not ambiguous and contains no manifest indexicals or hidden parameters. It may even be that what counts as believing varies from context to context. But shifts in context do not play a role in the following. We consider Pierre as he assents to "London is not pretty" and is disposed to assent to "Londres est jolie" in this very context. And we, the ascribers, do not undergo a change of context when we consider the question which beliefs can be ascribed to Pierre with principled justification. Hence for the purposes of our discussion, there seem to be no "contextualist" obstacles to using phrases like "the belief that London is pretty/not pretty".

15 Kripke $(1979$, pp. 249,263$)$ says that the principle of disquotation appears to be a self-evident truth. Being basic may explain why it seems self-evident.

16 For an elaboration of this account of belief expression see Kemmerling (2002) and (2003). 
To express a belief, then, is to provide a particularly strong kind of evidence for holding the belief in question. Someone who assents to the sentence "It's raining", satisfying the conditions of being sincere, not linguistically confused, etc., expresses the belief that it's raining; whereas someone who looks out of the window and subsequently puts on his raincoat before leaving the house does not, in the sense just outlined, express this belief, since there is no basic ascription principle to the effect that if someone does so, then, ceteris paribus, he believes that it's raining. If someone looks out of the window and then puts on a raincoat, this may be good evidence for his believing that it's raining, but it does not amount to his expressing this belief.

The first claim, then, is this: Pierre, in assenting to "London is not pretty" does not express the belief that London is not pretty. And the argument is this: (a) The modified disquotational principle cannot be invoked for ascribing this belief to Pierre on the strength of his assent (and his fulfilment of the conditions concerning sincerity, reflectedness, etc.). It cannot be invoked for the reason mentioned: His case is ruled out by the ceteris paribus clause of the principle, since he has a counterdisposition (namely to assent to "Londres est jolie"). (b) There is no other basic principle which could be invoked for ascribing this belief to Pierre on the strength of his assenting to "London is not pretty". Obviously, it would be difficult to prove this negative existential statement. But there is good reason for accepting it. For any other principle which could be invoked would have to be extremely similar, in the relevant respect, to the modified disquotational principle: it would have to permit, given normal conditions, to ascribe the belief on the strength of Pierre's sincere assent to the same sentence. And there is no reason to assume that there is another basic principle of this kind. But in case this support for (b) should seem too weak, here comes another reason: Any other principle of this kind would have to contain a ceteris paribus clause, and its application to Pierre's case would therefore lead to the same result as the modified disquotational principle.

So given Kripke's story, Pierre does not express the belief that London is not pretty. This does not establish that Pierre does not have this belief. Kripke ascribes to him this belief as a result of applying an incorrect principle of belief ascription. But even if Kripke's reasons for ascribing the belief to Pierre are misguided, it may nevertheless be true that Pierre holds the belief. Our result (that Pierre does not express the belief) only entails that there is no principled justification for the ascription of this belief to him on the strength of his assent. But he may nevertheless have it. Nothing Kripke says explicitly excludes this possibility. And the story is our only source of information about Pierre. 
Let me briefly sum up what I have said so far. We considered the question whether Pierre, in assenting to "London is not pretty", expresses the belief that London is not pretty. He expresses this belief iff a basic ascription principle, which is applicable to his case of assenting to this sentence, yields that he has the belief. Kripke assumes that there is such a principle, namely his disquotational principle. But this principle is not correct as stated by Kripke. The modified version contains a ceteris paribus clause. And Pierre's case is a paradigm of a case in which some relevant things are not normal, for Pierre's disposition to assent to "London is not pretty" comes hand in hand with a counterdisposition. Therefore the disquotational principle, in its modified version, does not justify our ascription of the belief to Pierre on the strength of his assenting to the sentence. And there is no other basic principle which would justify such an ascription (by us) to Pierre in those circumstances. Hence we are to conclude that (on the strength of nothing but this) the belief that London is not pretty cannot be ascribed to Pierre with principled justification, although he is a normal speaker who assents to "London is not pretty".

Strictly analogous considerations lead to the result that when he assents to "Londres est jolie", Pierre does not express the belief that London is pretty. So we have no principled justification for ascribing to him this belief either. But given these two negative results, we do not have principled justification for denying him the two beliefs in question. For, obviously, there are no basic principles of belief denial, accepted principles of the type "If someone does $x$, and conditions $c_{1}, \ldots, c_{n}$ are satisfied, then, ceteris paribus, he does not believe that $p$ ", which could be invoked to ascribe to Pierre lack of belief on strength of his assent to "London is not pretty" or "Londres est jolie".

Therefore, as far as Kripke's story goes, there is no accepted principle of belief ascription or belief denial which would justify any of the following claims:

(1) Pierre believes that London is pretty.

(2) Pierre believes that London is not pretty.

(3) Pierre does not believe that London is pretty.

(4) Pierre does not believe that London is not pretty.

Our standard practice of belief ascription and belief denial, insofar as it is governed by accepted principles, is silent about the truth or falsity of (1)-(4). In particular, we are not forced, by our standard practice, to accept (1) and (2). 
Does this result make Kripke's story less puzzling? Yes, I think so. At least in some respects. We don't have to ascribe to Pierre contradictory beliefs about London's pulchritude. Moreover, we are not committed to contradictory claims about Pierre's beliefs, as we would be, if we accepted the plausible principle "If $S$ believes that non- $p$ and is not disposed to assent to ' $p$ ', then $S$ does not believe that $p$ ". ${ }^{17}$

\section{Does Pierre have the beliefs?}

We have no principled justification for any of the claims (1)-(4). Still we may wonder if we have reason to consider certain of these claims true. Kripke claims that (1) and (2) are true, as result of the application of the disquotational principle ${ }^{18}$, and he gives separate arguments for the falsity of (3) and (4) which I shall consider in sections 6 and 7 below. Against Kripke, a case can be made for the claim that (3) and (4) are true. The reasoning is this. We cannot, with principled justification, ascribe to Pierre the belief that London is not pretty on the strength of his assenting to "London is not pretty". But as a normal speaker of English, is there anything better he could do to express the very belief that London is not pretty than assenting to this very sentence? ${ }^{19}$ No, since assent to a sentence which means that $p$ (and does not mean anything else) is the best possible means for expressing the very belief that $p{ }^{20}$ If the best possible means isn't good enough to do the trick, nothing is. So we are left with two possibilities: either assuming that Pierre holds the belief but is barred from expressing it, or assuming that Pierre does not hold the belief.

The first option-of assuming that Pierre holds a very simple belief which he cannot, given his current overall cognitive state, express, even when he does the optimal thing for expressing it-is highly extravagant. There might be inexpressible beliefs, but the belief that London is not

17 Kripke (1979, p. 255) says that Pierre is not disposed to assent to "London is pretty". Given this and the plausible principle, (2) entails (3); so accepting (1) and (2) would lead to accepting (1) and (3); i.e., we would contradict ourselves.

18 Brian Loar (1987, p. 170) agrees: "Kripke is surely right that our ordinary principles imply that (1) and (2) are both true".

19 I use the expression "assenting to sentence $s$ " in this paper as a technical umbrella term for all pertinent linguistic acts like answering the question " $s$ ?" affirmatively, asserting that $p$ (where " $p$ " refers to the propositional content of the utterance of $s$ in the circumstances), denying the claim that non- $p$, etc.

20 This claim is defended in Kemmerling $(1993,104 \mathrm{ff}$.) and in a different way in Kemmerling (2003, $214 \mathrm{ff}$.). 
pretty is not a plausible candidate. If Pierre had it, it would be very hard to account for the fact that he, a normal speaker who is capable of expressing indefinitely many of his beliefs, cannot express this one unexciting belief by using the linguistic means at his disposal which are most appropriate for expressing it. The most straightforward explanation seems that he does not have it. This is clearly not a compelling argument against the first option. Nevertheless, I shall leave the first option aside as clearly in need of defence, shifting the onus of argument to whomever wants to defend it.-So what about the second option?

Clearly, it looks harsh to deny Pierre the belief that London is not pretty. (But nota bene: the denial is very specific and restricted. It concerns nothing but exactly this one belief; there is no reason to deny Pierre similar beliefs, as, e.g., the belief that the city he lives in is not pretty, or the belief that London has turned out to be not pretty. Pierre may well express these similar beliefs; he has no counter-dispositions which would stand in the way.) Denying him the belief has troublesome consequences. For if he doesn't have this belief, it appears that he does not know, neither understand nor mean what he says when he sincerely assents to "London is not pretty", given that what he thereby says is that London is not pretty. So maybe in assenting he doesn't even say that? But then his status as a normal speaker is endangered, and this consequence runs against Kripke's presupposition that he is a normal speaker. We have accepted this presupposition and therefore should not deny that what he says by assenting to the sentence is that London is not pretty.

But we do not have to deny this. For his being a normal speaker (who says that $p$ in assenting to " $p$ ") is quite compatible with the fact that he does not always fully know, understand and mean what he says. The conceptual connections between (sincerely) saying that $p$, knowing (or understanding) what one says and meaning that $p$ are loose enough to allow for occasional exceptions. The relevant principles (e.g., "If a normal speaker sincerely says that $p$, then, ceteris paribus, he means that $p$ ") contain a ceteris paribus qualification, and in Pierre's case of saying that London is not pretty, this qualification, again, is not fulfilled.-It seems that even though it is prima facie not an attractive move, we may in all consistency deny that Pierre believes that London is not pretty (and analogously that he believes that London is pretty).

Since this line of reasoning applies to Pierre both as a normal speaker of English and as a normal speaker of French, we have reason-although not compelling reason-to reject claims (1) and (2) and to accept claims (3) and (4). It is clear why the reasoning hinted at here is far from being 
compelling: There are no basic principles of belief denial to the effect that if someone, even by employing the optimal means to this effect, is not capable of expressing the belief that $p$, he does not believe that $p$. We have no principled justification for claiming that Pierre does not have these beliefs, but only considerations which are defeasible and may seem far-fetched.

The upshot of all this so far is this: In the light of what Kripke tells us about Pierre, we are in a position to make a definite claim that there is no principled justification for accepting any of the statements (1)(4). As regards the truth value of these statements, we cannot make any definite claim, although the considerations just presented provide some reason-if no "knock-down arguments"-to reject statements (1) and (2), and to accept (3) and (4).

At one point, Kripke says that the puzzle is this: "Does Pierre, or does he not, believe that London is pretty?"21 Well, if this is the puzzle, then the solution may be this: He does not believe it. We have no principled justification for this answer, but it may turn out to be the best one, all things considered. Alternatively, we may be content to say that Kripke's story does not contain sufficient information for considered judgments about the truth values of (1)-(4). ${ }^{22}$

\section{A taxonomical suggestion}

In the foregoing, I assumed that the disquotational principle, as devised by Kripke, needs to be corrected by adding a ceteris paribus clause. The only reason I have given so far for this claim is that all such principles require such qualification. But I have left unspecified what marks out the class (or family) of "all such" principles. So let me turn to this question.

In this section, I shall propose a taxonomy of the generalizations in question. In the next section, I shall argue that the disquotational principle belongs in the category of those generalizations of which it is characteristic that they contain a ceteris paribus qualification essentially.

21 Kripke (1979), p. 259.

22 As to the Peter/Paderewski case which is introduced by Kripke (1979) later on in the paper (p. $265 \mathrm{f}$.), it should be noted that the disquotational principle cannot be applied in the first place. For Peter, as described by Kripke, ought not, on reflection, assent to "Paderewski had musical talent" at all. If he is asked to assent or dissent to this sentence, then, on appropriate reflection, he will do neither. He will first want to inquire which Paderewski is at issue. That is to say, Peter does not satisfy the antanodent of the diementational nrincinle 
The generalizations which I have in mind are those which concern the connections between normal people's states of minds, their behaviour (including actions) and features of situations in which they find themselves. Such generalizations can be exhaustively divided, in a philosophically instructive way, into four categories. I shall proceed by giving examples. (As regards one of these categories, I can give no examples; I presume it has no members which are known to us.) Let me try to explain what I have in mind.

The first category contains statements like the following:

If $x$ remembers that $p, x$ has not forgotten that $p$.

If $x$ believes that $p, x$ holds true that $p$.

If $x$ hopes that $p, x$ wishes that $p$.

If $x$ regrets that $p, x$ believes that $p$.

If $x$ knows that $p$, it is true that $p$.

These are straightforward trivialities which do not require a ceteris paribus qualification. They are unassailable analytic truths in the traditional sense of being a priori necessities, knowable to be true in virtue of linguistic competence concerning the words contained in them. I shall call this the Lexical category.

Another category, which I dub the Empirical, contains generalizations like these:

If $x$ abhors $y$, then $x$ does not like to think about $y$.

If $x$ is in noisy surroundings, $x$ finds it hard to concentrate continuously.

If $x$ is drunk, $x$ 's reactions are slowed.

Generalizations of this type require, I presume, the insertion of a ceteris paribus clause in order to sound feasible at all. But even when this qualification is added, they are clearly not analytic or conceptual truths. Consider the first example, with the qualification added:

If $x$ abhors $y$, then $x$, ceteris paribus, does not like to think about $y$.

Let's assume that this is true. But even on this assumption it is still possible that normal people are, or could become, different in this respect: i.e., it is possible that in normal conditions they like thinking about what they abhor. The generalization stays contingent, even under the ceteris paribus qualification. (This category divides into two subcategories: one which is designed to contain empirical generalizations without a ceteris paribus qualification, the other those which have such a qualification.) 
Now here come some examples of generalizations which (as soon as they are qualified by a ceteris paribus clause) I propose to subsume under the third category which I shall call the Conceptual category:

If $x$ wants $y$, thinks he can easily get $y$, and thinks that getting $y$ is O.K., $x$ tries to get $y$.

If $x$ tells $y$ that $p, x$ intends $y$ to believe that $x$ believes that $p$.

If $x$ believes that $p$ will come about only if he does $y$, and if he desires that $p$, and if he believes that his doing $y$ does not have any disadvantages which would outweigh the advantages of its being the case that $p$, then he will try to do $y$.

If $x$ fears $y$, then $x$ tries to avoid $y$.

Generalizations of this type we do not take, on reflection, to be exceptionless. (And if, unbeknownst to us, some of them were exceptionless, we would have no reason to believe so.) Without a ceteris paribus qualification, i.e., as statements of unrestricted generality, they are, for all we know, at best defeasible claims; some of them we even know to be false. But as soon as this qualification is added, they become conceptual truths, if they are true at all. It is, for example, not a contingent fact about the psychology of normal human beings that if they want something (and ...), they, ceteris paribus, try to get it. That normal people standardly (under normal conditions) could be or become different in this respect, is not a possibility. Our concepts of wanting something and trying to get something would have to be changed, if we were to allow for the possibility that normal people did not, in overall normal conditions, try to get what they want, given they think that getting it is easy and O.K. So in a case in which, for all we know, the antecedent of such a generalization is fulfilled but its consequent is not, we are justified a priori to conclude that some abnormality has arisen. It is part of our mastery of the relevant concepts, contained in such generalizations, that we do not accept any possible case as a genuine falsification of any of those generalizations.-These generalizations, when explicitly qualified by a general normality constraint, are analytic truths, but without such a qualification they would not be analytically true, and many of them would not be true at all.

It is quite clear that there is little hope of ever devising clear cut tests which would allow us definitely to assign every pertinent and true generalization to exactly one of them. But nevertheless, it is equally clear that these generalizations are so different in kind that it is a good idea to categorise them: 
the Lexical category is for analytic generalizations which require no ceteris paribus clause;

the Empirical category is for contingent generalizations with or without a ceteris paribus clause (if they contain such a clause, they are still contingent);

the Conceptual category is for analytic generalizations which are conceptually true exactly because they contain a ceteris paribus clause (i.e., if they are true, they are necessarily true; but if the clause is dropped, the result may be false).

I set out a simple schema below of the taxonomy I want to suggest. Think of all those true generalizations (in standard English) which concern the interrelationships between normal people's mental states, and the connections between their mental states, the circumstances in which they find themselves, and their behaviour. (It should in no way be assumed that generalizations of this kind are, or may serve as, lawes of the special sciences or of commonsense psychology. ${ }^{23}$ ) They can be divided into those generalizations which contain a ceteris paribus qualification and those which do not. Both categories can be divided again into contingent and necessary. Schematically, we get this: ${ }^{24}$

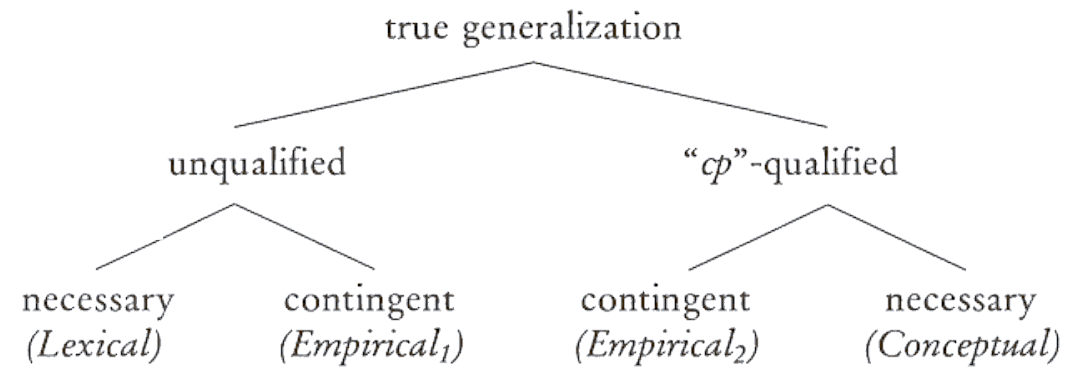

23 It may well be true, as, e.g., Earman/Roberts (1999) argue, that what are called ceteris paribus laws in the special sciences really are vague claims of "work-in-progress theories" (p. 471) and "belong to the context of discovery rather than the context of justification" (p. 466). It may even be true, as, e.g., Keil (2005) argues that there are no such things as ceteris paribus laws at all. And Schiffer (1991) may be right in conceding that there are true propositions expressed by ceteris paribus sentences of commonsense psychology and yet doubting that there are commonsense psychological ceteris paribus laws. All I shall presuppose here is that there are true general sentences of the type under consideration.

24 This schema would need refinement, if there were generalizations which are a priori and not necessary, or a posteriori and necessary. But I know of no such examples. 
A few more remarks about these categories. The Lexical category consists of generalizations which for the most part will be too trivial to elucidate the concepts involved. Normally, any attempt at denying one of them would raise serious doubts about having mastered the linguistic meaning of all words contained in the generalization. - Leaving vacuously true generalizations aside, the category dubbed Empirical ${ }_{1}$ probably does not contain a single member which we know to belong in this category. The examples given above require a ceteris paribus qualification, and hence belong to the category dubbed Empirical 2 .

The generalizations to be subsumed under the category Conceptual may be called $c p$ necessities. They are not only true but unassailably true (a priori recognizable as necessary) as they stand, yet without their requirement of overall normality they inevitably turn into falsehoods or at least into defeasible statements (a priori recognizable as not necessary). I want to note two things which are remarkable about $c p$ necessities: their embedded generalizations, though contingent, are different from standard empirical generalizations; and the normality-operator functions in a peculiar way when applied to these special generalizations. For the ease of discussion, let us describe their form, crudely, as

Given overall normal conditions: whenever $A, B$

or even more crudely as

$$
c p(A \rightarrow B) \text {. }
$$

And let us still concentrate only on necessarily true statements of this type. As to the first point, the unqualified generalization contained in $c p$-necessities is different from empirical generalizations with respect to an important modal feature: " $A \rightarrow B$ " is contingent, but not thoroughly contingent. (A generalization is thoroughly contingent, if it is possibly true and it is possibly false even when its antecedent is realized in normal circumstances.) " $A \rightarrow B$ ", if true, cannot be false in cases in which overall normal conditions obtain. Therefore, " $A \rightarrow B$ " is not a thoroughly contingent generalization. If such an unqualified generalization is true, its being true is, of course, a contingent fact; yet the generalization itself is not thoroughly contingent. This modal feature of " $A \rightarrow B$ " is well captured by the qualified generalization, " $c p(A \rightarrow B)$ ", which entails its necessity, and therefore rules out the possibility that " $A \rightarrow B$ " is false in overall normal circumstances.

Secondly, it is worth emphasising how drastically the normality constraint, as used in $c p$ necessities, differs from its use in empirical generalizations. " $c p(A \rightarrow B)$ ", if it is a generalization of this type, is a priori 
recognizable as a necessary truth, although " $A \rightarrow B$ " may be known to be false. Hence in $c p$ necessary statements, the semantic tie between "overall normality" and the words contained in "Whenever $A, B$ " has to be of a very special sort, quite different in kind from what we find in generalizations in the Empirical 1 category. Many scientifically minded people will be inclined to detest any non-negating operator which is able to transform known falsehoods into conceptual truths. Certainly, this transformation is a remarkable feat. But it is not performed by the $c p$-operator alone, but rather in semantic cooperation with the specific vocabulary contained in " $A$ " and " $B$ ". The right kind of semantic interplay is clearly needed, for in its usual applications in science, the $c p$ operator does not have the magical power to transform falsified or falsifiable generalizations into unassailably true ones, but only the quite unexciting power to transform them into generalizations which are harder, though not impossible, to falsify. One may suspect that the vocabulary needed for the normality-operator to develop its wondrous powers, is the vocabulary of so-called "folk psychology", "folk-ethics", "folk-aesthetics", etc. (If $c p$ necessary generalizations form the core of so-called "folk psychology", it is little surprise that folk psychology is nauseating for anyone who wants to construe it as an empirical theory.)

All of the unqualified generalizations of true $c p$ necessities may be actually false, so the $c p$ necessities are true in virtue of their normalityconstraint and how it semantically interacts with the vocabulary of what follows them. Since they are conceptual truths irrespective of the truth value of the generalization contained in them, I shall say that $c p$ necessities contain their normality-constraint essentially.

\section{Why the Disquotational Principle requires a ceteris paribus qualification}

Now let us ask to which of these categories the following principle, $(\mathrm{P})$, which is a reformulation of Kripke's original version of the disquotational principle, should be assigned:

(P) If $x$ (a normal English speaker), on reflection, sincerely assents to " $p$ " (an appropriate English sentence), then $x$ believes that $p$.

Let us pretend that $(P)$ is true as it stands. Then it would have to belong either to the Lexical category or to the Empirical 1 category. If it belonged to the latter, then it would have to be a contingent truth, and therefore possibly false. At the same time it is not possible that $(P)$ is false in normal cases. It is not possible, that is to say, that normal speakers 
who, on reflection, sincerely assent to some sentence of their language in overall normal circumstances do not believe what they thereby say. To put (P) in the Empirical 1 category is to ignore this modal fact.

May (P) belong to the Lexical category? Clearly not. For even if $(P)$ were true, it would not be a trivial truth to be accepted as self-evident by any competent speaker. (P), even if it were true, would not be analytic in the blatant way which is characteristic of the members of the Lexical category. (P), as it stands, is, I presume, something which is held to be in principle defeasible or contestable by most normal speakers. ${ }^{25} \mathrm{~A}$ normal speaker who perfectly understands the linguistic meaning of $(\mathrm{P})$, a speaker who knows the meanings of all expressions involved and who understands the semantic contribution of the grammatical structure, may nevertheless have, or come to have, second thoughts about the truth of $(P)$. (P), unlike for example trivial analytic truths like "He who believes something, holds it true", does not demand the unqualified assent of anybody who deserves to be regarded as a normal speaker of English. Why then do some people tend to think of $(\mathrm{P})$ as a Lexical truth? The reason may be this: They confuse (P)'s being not thoroughly contingent with its not being contingent; or they tacitly assume that $(\mathrm{P})$ is meant to cover only normal cases, i.e., they read $(\mathrm{P})$ as if it contained a ceteris paribus clause.

If $(\mathrm{P})$ is qualified by a normality constraint, the resulting modified disquotational principle, $(C p-P)$, cannot be subsumed under the $E m$ pirical $_{2}$ category. The reason is this. If $(C p-P)$ were contingent, then its negation would have to be possible. But then it would have to be possible that, given overall normal conditions, a normal speaker assents to " $p$ " while not believing that $p$. Again, this is not a possibility our concepts of normality, assent and belief would allow for.

Therefore, if $(C p-P)$ belongs to one of the categories, it belongs to the one I have dubbed the Conceptual. Subsuming $(C p-P)$ under this category immediately accounts for the modal fact mentioned above: It is not possible that normal speakers who, on reflection, sincerely assent to some sentence of their language under overall normal conditions do not believe what they say in their assentings.

It may be asked whether it belongs to any these categories. I certainly think so. But this assumption is not beyond any reasonable doubt. For one thing, there is the possibility that this vaguely sketched typol-

25 Even Kripke (1979, p. 249) seems to admit this, when he says: "I fear that even with all this [i. e. 'normal speaker', 'on reflection' and 'sincerely', A.K.] it is possible that some astute reader ... may discover a qualification I have overlooked, without which the asserted principle is subject to counterexample". 
ogy of generalizations fails in some grand, principled way, as some naturalist philosophers (and anyone else who altogether rejects the idea of conceptual truths) would certainly be inclined to object. But I shall not go into this. Rather I shall assume without argument that the four categories which I have introduced could be specified sufficiently clearly and distinctly, and conclude my sketch of the argument by repeating its conclusion: Kripke's disquotational principle has to be modified, and its modified version belongs to a category of generalizations of which it is characteristic that if they are true, they are conceptual truths containing a ceteris paribus qualification essentially.

\section{Kripke's argument against (3)}

In conclusion, I want to consider the objections which Kripke raises against two claims which are at least tenable, as I argued in section 3 above, namely,

(3) Pierre does not believe that London is pretty.

(4) Pierre does not believe that London is not pretty.

Against (3), Kripke argues as follows: "It seems undeniable that Pierre once believed that London is pretty-at least before he learned English" ${ }^{26}$ We should clearly accept this much. Kripke goes on:

Should we say that Pierre, now that he lives in London and speaks English, no longer believes that London is pretty? Well unquestionably Pierre once believed that London is pretty. So we would be forced to say that Pierre has changed bis mind, has given up bis previous belief. ${ }^{27}$

No, we are not forced to say such a thing; we may say instead that he has lost his previous belief without being aware of this fact. Kripke continues:

But has he really done so? Pierre is very set in his ways. He reiterates, with vigor, every assertion he has ever made in French. He says he has not changed his mind about anything, has not given up any belief. Can we say he is wrong about this? If we did not have the story of his living in London and his English utterances, on the basis of his normal command of French we would be forced to conclude that he still believes that London is pretty. And it does seem that this is correct. Pierre has neither changed his mind nor given up any belief he had in France. ${ }^{28}$

26 Kripke (1979), p. 256.

27 Kripke (1979), p. 256.

28 Kripke (1979), p. 256. 
Well, it should be conceded that Pierre has not changed his mind; to say that would be to misdescribe what happened to him. If giving up a belief requires being conscious of doing so, then, again, it would be a misdescription of what happened to Pierre's belief that London is pretty to characterize it as one which he has given up. But nevertheless, Pierre has lost this belief. Pierre's averring that he still believes everything he believed in France is irrelevant; he has no special authority about this. ${ }^{29}$ He may be prepared to assent to every French sentence he assented to when he lived in France, in which case he would not have lost any relevant disposition. But this does of course not show that his assent today is an expression of the same belief as it used to be. The problem with him is that in the meantime he has acquired other relevant dispositions-new dispositions which have an influence exactly on the expressive power of his current assentings. Kripke's considerations contain nothing to refute this point.

\section{Kripke's argument against (4)}

Finally, let's turn to Kripke's objection against the claim that Pierre does not believe that London is not pretty.

Similar difficulties beset any attempt to deny him his new belief. His French past aside, he is just like his friends in London. Anyone else, growing up in London with the same knowledge and beliefs that he expresses in England, we would undoubtedly judge to believe that London is not pretty. Can Pierre's French past nullify such a judgement? Can we say that Pierre, because of his French past, does not believe that [London is not pretty] ?0 $^{30}$

Well, this is the wrong question to ask at this point. For it is not Pierre's French past which is important, it is his present disposition to assent to "Londres est jolie" and his present status as a normal speaker of French. Kripke goes on:

Suppose an electric shock wiped out all his memories of the French language, what he learned in France, and his French past. He would then be exactly like his neighbors in London. He would have the same knowledge, beliefs, and linguistic capacities. We then presumably would be forced to say that Pierre believes that London is ugly if we say it of his neighbors. But surely no shock that destroys part of Pierre's memories and knowledge can give him a new belief. If Pierre believes [that London

29 Does Pierre lack the kind of self-knowledge which normal people have about their current beliefs? Does he think that he has a certain belief which in fact he doesn't have? Or does he have a belief of which he thinks that he doesn't have it? I have argued that no such conclusion can be drawn in Kemmerling (2005).

30 Kripke (1979), pp. $256 \mathrm{f}$. 
is not pretty] after the shock, he believed it before, despite his French language and background. 31

This last remark seems to be just wrong. If after the shock Pierre has lost his disposition to assent to "Londres est jolie", then the troublemaker is gone, and his assent to "London is not pretty" acquires full expressive power. Now, in the absence of counter-dispositions, the disquotational principle can be applied, in good faith, to assenting Pierre as to a case in which, as far as we can tell, cetera are paria. Again, Kripke's considerations contain nothing to refute this point.

\section{Conclusion}

So one lesson which may be learnt from considering Kripke's puzzle about Pierre concerns the disquotational principle. It should be improved. This could be done by adding two items: first, a clause which explicitly excludes counter-dispositions; secondly, a ceteris paribus qualification in order to exclude future counter-examples:

If a normal English speaker, on reflection, sincerely assents to " $p$ " and has no counter-dispositions, then, ceteris paribus, he believes that $p$.

Alternatively, we might rather formulate the principle simply as follows:

If a normal English speaker assents to " $p$ ", then, ceteris paribus, he believes that $p$

and collect on a separate list those features which we have recognized up to date as violating the principle's overall normality constraint (i.e.: insincerity, rashness, linguistic or conceptual confusion, and counter-disposedness).

Let me emphasise that the ceteris paribus clause must stay. Adding merely the constraint concerning counter-dispositions would not do. Without the ceteris paribus clause, even the enriched principle would be nothing but a defeasible generalization awaiting another counterexample. ${ }^{32}$ We have no reason to assume that our current list of relevant abnormalities is complete. As a conceptual generalization, the principle requires the ceteris paribus clause essentially. "Taken in its obvious intent, after all, the principle appears to be a self-evident truth", says Kripke. ${ }^{33}$ I agree, and would add: Taken in its obvious intent, the

31 Kripke (1979), p. 257.

32 J.G. Moore's (1999) examples for what he calls cases of "misdisquotation" might be considered further counter-examples against the "final" version of the principle if it were stated without the $c p$-clause.

33 Kripke (1979), p. 249. 
principle contains a normality constraint which we tend to overlook only because it goes without saying.

The requirement concerning overall normality which is articulated in the ceteris paribus clause is not a particularly precise constraint. But we should, I think, not complain about this. It seems to be a fact about our practice of belief ascription which several authors have noted. J.G. Moore thinks that "we cannot [...] articulate a steadfast disquotation principle that is at once precise, theoretically useful, and also noncontroversially true". ${ }^{34}$ And with regard to Kripke's unqualified disquotational principle, J.I. Biro has noted that "there is no question but that we observe caution in our use of disquotation in everyday interpretation". ${ }^{35}$ I agree with both claims. The occurrence of the ceteris paribus clause in the modification of the principle suggested in this paper can be looked upon as a way of making explicit the source and the sort of imprecision which is a characteristic feature of the disquotation principle; at the same time, it is an essential part of what makes this principle non-controversially true. Moreover, the occurrence of this clause is an apt reminder that we should observe caution in our use of the principle.

I have not tried to inquire into what exactly are the philosophical points that Kripke wanted to make by his discussion of Pierre's case. But if part of his intention was to reveal how, in cases which are clearly possible, the principles underlying our common practice of belief ascription "are questionable" ${ }^{36}$, how they lead into grave difficulties (how we are forced by them, all too easily, to ascribe contradictory beliefs, and even to contradict ourselves), then I think that he has not shown this. In its modified version, the disquotational principle does not yield such results. ${ }^{37}$

\section{Andreas Kemmerling}

Philosophisches Seminar

Universität Heidelberg

Schulgasse 6

D-69117 Heidelberg

andreas.kemmerling@urz.uni-heidelberg.de

34 Moore (1999), pp. $362 \mathrm{f}$.

35 Biro (1984), p. 281.

36 Kripke (1979), p. 268.

37 Thanks to Tyler Burge, Gerhard Ernst, Mark Helme, Nikola Kompa, Götz Klages, Wolfgang Künne, Brian Loar, Tobias Rosefeldt, Eike von Savigny, Wolfgang Spohn and Stephen Schiffer for helpful, even if incredulous, comments on earlier versions of this paper. Special thanks to Fred Dretske for encouragement. 


\section{References}

Biro, J.I., 1984, What's in a Belief?, Logique et Analyse 27, pp. 267-282. Donnellan, K., 1989, Belief and the Identity of Reference, in: French et al. 1989, pp. 275-288.

Earman, J. and Roberts, J., 1999, Ceteris paribus, there is no Problem of Provisos, Synthèse 118, 439-478.

Feit, N., 2001, Rationality and Puzzling Beliefs, Philosopby and Phenomenological Research 63, pp. 29-55.

French, P.J., Uehling, T., and Wettstein, H. (eds.), 1981: Midwest Studies in Philosophy: Foundations of Analytic Philosophy. Notre Dame: University of Notre Dame Press.

Keil, G., 2005, How the ceteris paribus Laws of Physics Lie, in: J. Faye, P. Needham, U. Scheffler and M. Urchs (eds.), Nature's Principles, Dordrecht: Springer, pp. 167-200.

Kemmerling, A., 1993, The Philosophical Significance of a Shared Language, in: R. Stoecker (Hrsg.), Reflecting Davidson-Donald Davidson Responding to an International Forum of Philosophers, Berlin/New York 1993, 85-116.

Kemmerling, A., 2002, Expressing an Intentional State, in: G. Grewendorf/G. Meggle (eds.), Speech Acts, Mind and Social Reality, Dordrecht 2002, 83-92.

Kemmerling, A., 2003, Belief ascription: Objective sentences and Soft Facts, Facta Philosophica 5, 203-222.

Kemmerling, A., 2005, Zu einem Problem der Selbstkenntnis in Kripkes vermeintlichem Rätsel über das Glauben, in: A. Newen/G. Vosgerau (Hrsg.), Den eigenen Geist kennen, Paderborn 2005, 83-97.

Kripke, S., 1979, A Puzzle about Belief, in: A. Margalit (ed.), Meaning and Use, Dordrecht: Reidel, pp. 239-283.

Lewis, D., 1981, What Puzzling Pierre does not believe, Australasian Journal of Philosophy 59, pp. 283-289.

Loar, B., 1987, Names in Thought, Philosophical Studies 51, pp. 169185.

Marcus, R.B., 1981, A Proposed Solution to a Puzzle about Belief, in: French et al. 1989, pp. 501-510.

Moore, J.G., 1999, Misdisquotation and Substitutivity, Mind 108, pp. 335-365.

Over, D.E., 1983, On Kripke’s Puzzle, Mind 92, pp. 253-256.

Schiffer, S., 1991, Ceteris paribus Laws, Mind 100, pp. 1-17.

Sosa, D., 1996, The Import of the Puzzle about Belief, Pbilosophical Review 105, pp. 373-402. 